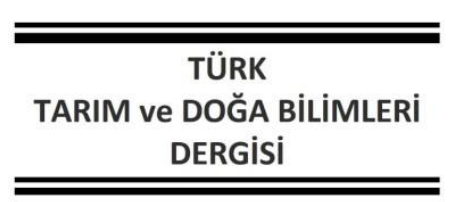

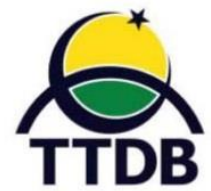

www.dergipark.gov.tr/turkjans

Araştırma Makalesi

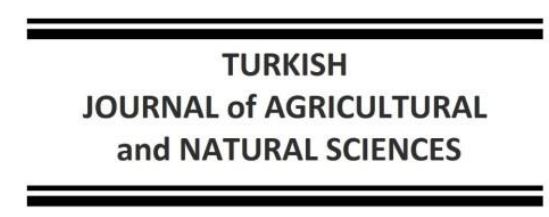

and NATURAL SCIENCES

\title{
Bingöl-Guldar Domatesinin Besin Elementi İçeriklerinin Karşılaştırılması
}

\author{
Ali Rıza DEMIRKIRAN ${ }^{1}$ \\ ${ }^{1}$ Bingöl Üniversitesi, Ziraat Fakültesi, Toprak Bilimi ve Bitki Besleme, Bingöl \\ Sorumlu yazar: ademirkiran@bingol.edu.tr
}

Geliş Tarihi: 14.06.2021 Düzeltme Geliş Tarihi: 29.06.2021 Kabul Tarihi: 01.07.2021

Öz

Bitkisel ürünlerin farklı farklı özellikleri olmasından dolayı bitkilerin besin içeriklerine yönelik çalışmaların yapılması çok önemlidir. Bu araştırma, Bingöl-Guldar ismiyle anılan köy domatesinin besin elementi içeriklerinin belirlenip, diğer domateslerin içerikleriyle karşılaştırılmasına yönelik olarak yürütülmüştür. Bu kapsamda, hem yörede yetiştirilen diğer domates bitkilerinin besin elementi içerikleri ( 7 adet sofralık domates genotipi), hem de daha önce domatesin besin elementi içerikleri konularında yapılmış olan diğer çalışmalarda bulunan değerlerin karşılaştırmalı olarak bir değerlendirilmesi yapılmıştır. Sonuçlara dikkat edildiğinde, Guldar domatesinin meyvesinde yapılan analizlerin makro elementlerden fosfor ve potasyum konsantrasyonlarının diğer genotiplerden daha fazla bulunduğu belirlenmiştir. Guldar domatesi genotipinde bulunan mikro elementlerden ise mangan elementi içeriğinin diğer genotiplere nazaran daha yüksek konsantrasyonda olduğu tespit edilmiştir.

Anahtar kelimeler: Guldar, Bingöl, domates genotipleri, bitki besin elementi içeriği.

\section{Comparison of Nutrient Element Contents of 'Bingol-Guldar' Tomatoes}

\begin{abstract}
Since plant products have different properties, it is very important to carry out studies on the nutritional contents of plants. This research was carried out to determine the nutrient content of the village tomato, which is called Bingöl-Guldar, and to compare it with the contents of other tomato genotypes. In this context, a comparative evaluation was made of the nutrient content of other tomato plants ( 7 table tomato genotypes) grown in the region, as well as the values found in other studies on the nutrient content of tomatoes. Considering the results, it was determined that the macro elements made on the fruit of the Guldar tomato had higher concentrations of phosphorus and potassium than the other genotypes. Among the micro element contents of Guldar tomato genotype, manganese element content was determined at a higher concentration than the other genotypes.
\end{abstract}

Key words: Guldar, Bingöl, tomato genotypes, plant nutrientsstability, plant nutrients.

\section{Giriş}

Dünya ve ülkemizde domates bitkisi (Solanum lycopersicum L.) yaygın olarak yetiştirilmekte ve gıda olarak devamlı tüketilmektedir. Domates tüketimi taze, işlenmiş, kurutulmuş ve turşu olarak kullanımının yanında, içerdiği vitamin, besin maddesi ve diğer etkili maddeler dolayısıyla da insan beslenmesinde önemli bir yer işgal etmektedir.
Solanaceaefamilyasından olan domates ülkemizin ekonomisine de önemli katkılarda bulunmaktadır.

Domatesin mineral içeriği (makro-mikro), tat ve kalite parametrelerin etkileyen bir faktördür (Fernades-Ruiz ve ark., 2011). Bitkilerin besin madde içerikleri pek çok etken tarafından etki altında kalmaktadır (Sanders ve ark., 1981). Domatesteki makro-mikro olmak üzere besin elementlerinin konsantrasyonları kalite parametresi olması yanında, ürünün muhafazasını 
da etkileyen faktörlerdendir (Rijck ve Schrevens, 1998). Killi topraklarda daha yüksek mineral madde içeriği olduğu ve bunun meyvenin vitamin ve mineral madde içerikleri üzerine önemli etki ettiği belirtilmiştir (Dorais ve ark., 2008).

Domates bitkisine gübre olarak uygulanan besin maddelerinin cinsi ve miktarı verim yanında, kalite ve kalite ve Pazar ile ilgili unsurları da etkilediği belirtilmiştir (Sainju ve ark., 2003). Hidroponik ortamlardaki yetiştirmede meyvenin besin madde içeriğinin daha kolay değiştirebildiği bildirilmiştir (Hernandez Suzarez ve ark., 2007). Domates bitkisinin besin elementi açısından yeterli kabul edilen düzeyleri şöyle belirlenmiştir; N: \%3.24.5, P: \%0.5-1.2, K: \%5-10, Ca: \%1.5-2.4, Mg: \%0.30.8, Fe: $60-300$ ppm, Zn: 20-250 ppm, Mn: 50-250 ppm, B: 25-75 ppm, Cu: 5-50 ppm (Jones ve ark., 1991).

Domates meyvelerindeki mineral madde içerikleri üzerine yapılan daha önceki bazı çalışmalar; meyvenin mineral madde içerikleri üzerine çeşitlerin, ilgili yetiştirme şartlarının ve yetiştirme metotlarının önemli etkileri olduğunu göstermiştir (Premuzic ve ark., 1998; Gunderson ve ark., 2001; Guil-Guerrero ve Rebolloso-Fuentes, 2009).

Pegasus F1 domates çeşidinin 11 farklı ticari domates anacı üzerine aşılanarak farklı EC düzeylerinin etkileri incelenmiştir. Çalışmada, $P, K$, $\mathrm{Ca}, \mathrm{Mg}, \mathrm{Fe}, \mathrm{B}, \mathrm{Mn}$ ve $\mathrm{Zn}$ düzeyleri incelenmiş, EC artışıyla $\mathrm{P}, \mathrm{K}, \mathrm{Mn}$ ve $\mathrm{Zn}$ içeriği artışı, $\mathrm{Ca}, \mathrm{Mg}$, Fe ve $\mathrm{B}$ içeriği azalması gözlenmiştir. En yüksek mineral madde içerikleri $\mathrm{P}$ için \%0.44-0.45 olarak (KemeritYedi RZ anaçlarında), K için \%4.4-\%4.1 olarak (Unifort-Heman, Yedi RZ, Spirit anaçlarında), Ca için \%0.45-0.44 olarak (Kemerit-Maxifort anaçlarında), $\mathrm{Mg}$ için \%0.24-0.22 olarak (Toro-Yedi RZ anaçlarında), Fe için 59-58 ppm olarak (Yedi RZToro anaçlarında), B için 20-18 ppm olarak (BodyToro anaçlarında), Mn için 16-14 ppm olarak (BodySpirit, Yedi RZ, Kemerit, Maxifort, Heman anaçlarında), Zn için 21-20 ppm olarak (Yedi RZBeafort, Kemerit, Toro, Resistar anaçlarında) bulunmuştur. Genel olarak Kemerit ve Yedi RZ anaçlarında besin elementinin fazla olduğu belirtilmiştir (Söylemez ve Pakyürek, 2017).

Günümüzde dengeli gübreleme ve bilinçli yetiştiricilik ile hem en fazla ürün alabilme hem de kaliteli ürün elde etme mümkün olmaktadır. Bunun yanı sıra aşırı gübreleme ve bilinçsiz yapılan bitki yetiştirme yöntemleri de hem toprak-su kirliliğine neden olabilmekte hem de verimde kayıplara sebep olmaktadır. Özellikle taze tüketilen sebzelerden domates, salatalık gibi sebzelerin özellikle azot alımı yüksek olup, bunlarda aynı zamanda nitrat içeriği de yüksek olmaktadır. Fakat aşırı kullanılan azotlu gübrelerin bu meyvelerde nitrat birikimine neden olduğu da bilinmektedir.

İzmir-Ödemiş’te yapılan bir çalışmada, azotlu gübrelerin uygulanmasiyla domates meyvesinin toplam $\mathrm{N}$ içeriğinin \%2.2-3.1 arasında, P'nin \%0.38-0.54 arasinda, K'nın \%2.8-3.3 arasında, Ca'nun \%0.11-0.48 arasında, Mg'nin \%0.13-0.24 arasinda, Fe'nin 42-78 ppm arasinda, Zn'nin 11-22 ppm arasında, Mn'nin 10-19 ppm arasında, Cu'nun 8-14 ppm arasında, Na'nın \% 0.05-0.08 olduğu bildirilmiştir (Ceylan ve ark., 2001).

Şimşek, Daylos, Bufalo, Tybif, Ty12Rz ve Newton domates çeşitleri üzerine yapılan bir çalışmada meyvenin besin elementi içerikleri aşağıdaki aralıklarda belirlenmiştir; N: \%2.0-3.8, P: \%0.4-0.8, Mg: \%0.4-0.7, K: \%2.8-4.5, Ca: \%0.4-0.7, Fe: 61-119 ppm, Zn: 20-39 ppm, Cu: \%7-14 ppm ve Mn: \%16-23 ppm (Budak, 2015).

Çukurova Üniversitesi gen havuzundaki 20 domates genotipi ve 2 ticari çeşit ile yapılan çalışmada meyvenin elementel içerikleri şu şekilde tespit edilmiştir: P: $13-29 \mathrm{mg} 100 \mathrm{~g}^{-1}$, K: $55-78 \mathrm{mg}$ $100 \mathrm{~g}^{-1}, \mathrm{Mg}: 1.3-5.3 \mathrm{mg} 100 \mathrm{~g}^{-1}$, Ca: $14-48 \mathrm{mg} 100 \mathrm{~g}^{-}$

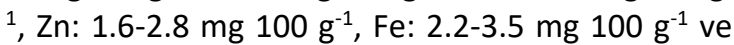
Cu: 0.5-2.2 mg $100 \mathrm{~g}^{-1}$ (Dere ve ark., 2018).

Hernandez Suarez ve ark. (2007) domates meyvesindeki P konsantrasyonunu 24-30 mg $100 \mathrm{~g}^{-}$ 1 , K konsantrasyonunu 244-260 mg $100 \mathrm{~g}^{-1}, \mathrm{Mg}$ : 9-

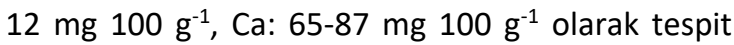
etmişlerdir. Sainju ve ark. (2014) çalışmalarında P içeriğinin $27 \mathrm{mg} 100 \mathrm{~g}^{-1}, \mathrm{~K}$ içeriğinin $244 \mathrm{mg} 100 \mathrm{~g}^{-1}$ olduğunu bildirmişlerdir. Bjelić ve ark. (2005) tarafından $\mathrm{Zn}$ konsantrasyonunun $0.12-0.15 \mathrm{mg}$ $100 \mathrm{~g}^{-1}$, Fe konsantrasyonunun 0.22-0.28 mg $100 \mathrm{~g}^{-}$ 1, Cu'nun $0.050 \mathrm{mg} 100 \mathrm{~g}^{-1}$ olduğu, Bosiacki ve ark. (2009) tarafından Fe konsantrasyonunun 1.29-5.54 mg $100 \mathrm{~g}^{-1}, \mathrm{Cu}^{\prime}$ nun 0.12-0.76 mg $100 \mathrm{~g}^{-1}$, aralarında olduğu bildirilmiştir.

FAO/WHO tarafından belirtilen, insan sağlığı açısından domates meyvesindeki mikro elementlerden çinko, bakır ve mangan elementlerin izin verilen en yüksek sınır değerleri 60 ppm Zn, 40 ppm Cu ve 500 ppm Mn'dır (CAC, 2001; CAC 2011; Lente ve ark., 2014).

Bölgede yapılan domates ile ilgili diğer çalışmalarda aşağıdaki sonuçlarla karşılaşılmıştır:

Demir ve Sahin (2017) süren atık suyu ve kısıtlamalı su uygulayarak Bingöl'de domates bitkisi (Joker-F1 hibriti) yetiştirdikleri iki yıllık denemelerinde, meyvelerin ortalama element içeriklerinin $\mathrm{N}$ : \%2.02-3.06, K: \%2.68-2.36, Ca: \%1.03-1.70, Mg: \%0.14-0.34, Zn: 23-29 ppm, Cu: 8$12 \mathrm{ppm}, \mathrm{Mn}: 18-34$ ppm olduğunu bildirmişlerdir. Demir ve ark. (2019), topraklardaki Ca noksanlığının Bingöl koşullarında domateste 
kökucu çürüklüğü hastalığına neden olduğunu belirtmişlerdir.

Bingöl'de 'Guldar' ismiyle anılan köy domatesinin coğrafi işaret almasına yönelik 7 adet sofralık domates genotipinin morfolojik, fizyolojik, kimyasal ve verim özelliklerinin belirlenmesi amacıyla yürütülen çalışmada, en yüksek domates verimi ( $5914 \mathrm{~kg} / \mathrm{da}$ ) Guldar domates genotipi ile en düşük domates verimleri Kuzeyköy ve Lice genotiplerinden (sırasıyla 3197 ve 3313 kg/da) elde edildiği belirtilmiştir. En yüksek tat-aroma değerinin (4.44) yine Guldar genotipinde tespit edildiği; en düşük tat-aroma değerinin (2.51) ise Aspem genotipinde bulunduğu belirtilmiştir. Ayrıca, Guldar domatesinin bulunduğu coğrafya koşullarında veriminin daha iyi olduğu ve kendine has özellikleri ile ön plana çıktığı bildirilmiştir (Özbay, 2021).

Bu araştırma, Bingöl'de 'Guldar' ismiyle anılan köy domatesinin besin elementi içeriklerinin belirlenmesi ve diğer bazı domates çeşitlerinin besin elementi içerikleri ile karşılaştırılması amaçlı olarak yürütülmüştür.

\section{Materyal ve Metot}

Bu araştırma, 2019 yılında Bingöl Merkeze bağlı Akdurmuş (Guldar) Köyünde, bir örnek çiftçinin arazisinde (Konum: 3850'34"K, $\left.40^{\circ} 28^{\prime} 36^{\prime \prime D}\right)$ yürütülmüştür. Domates genotipleri köy sınırları içerisinde iki farklı lokasyonda açık tarla koşullarında, tesadüf blokları deneme desenine göre üç tekerrürlü ve her tekerrürde 15 bitki olacak şekilde yetiştirilmiştir. Çalışmada, bitkisel materyal olarak, çeşit veya köy popülasyonu özelliği gösteren 7 adet domates genotipi kullanılmıştır (Çizelge 1). Denemeye başlamadan önce her iki lokasyonda da arazilerin genelini temsil edecek şekilde $0-30 \mathrm{~cm}$ derinlikten alınan toprak örnekleri Tarım ve Orman Bakanlığı, Doğu Anadolu Tarımsal Araştırma Enstitüsü Toprak ve Bitki Besleme Laboratuvarında analiz edilmiş ve bu örneklere ait analiz sonuçları Çizelge 2'de verilmiştir. Domates genotiplerinden bazıları hazır fide olarak temin edilirken bazıları için de Bingöl Üniversitesi Tarımsal uygulama ve Araştırma Merkezine ait seralarda fide üretimi gerçekleştirilmiştir. Domates fideleri 5-6 gerçek yapraklı oldukları dönemde sıra arası $140 \mathrm{~cm}$ ve sıra üzeri $50 \mathrm{~cm}$ olacak şekilde araziye dikilmiştir. Deneme boyunca arazi ve bitkilerde tüm temel bakım işleri Vural ve ark. (2000)'e göre yürütülmüştür. Araştırma süresince gerçekleşmiş olan bazı iklim verileri Çizelge 3'de verilmiştir.

Tekniğine uygun olarak üretilen domates genotiplerinden elde edilen meyvelerde besin elementi içerikleri aşağıdaki metodlar takip edilerek belirlenmiştir:
Mineral madde analizinde kullanılan meyveler 3. salkımdaki meyvelerden alınmış ve kuru yakma yöntemine göre analiz edilmiştir. Hasat edilen meyvelerden her tekerrür için 5 adet meyve alınmış, dilimlenmiş ve $65{ }^{\circ} \mathrm{C}$ sıcaklıktaki etüvde sabit ağırlığa gelinceye kadar kurutulmuş ve kuru örnekler porselen havanlarda öğütülmüştür. İnce öğütülmüş meyve örnekleri, krozeler içerisine 0.50 g tartılmış ve $550{ }^{\circ} \mathrm{C}$ sıcaklıktaki kül fırınında beş buçuk saat süreyle yakılmıştır. Yakma işleminden sonra elde edilen kül üzerine, 2 M'lık $3 \mathrm{ml}$ hidroklorik $(\mathrm{HCl})$ asit ilave edilmiş ve $50 \mathrm{ml}$ 'lik balon jojeler içerisine, mavi bant filtre kağıdı ile süzülmüş ve balon içeriği saf su ile balon çizgisine kadar tamamlanmıştır. Kaçar (1995) tarafından belirtilen şekilde elde edilen süzükteki $\mathrm{Cu}, \mathrm{Zn}, \mathrm{Mn}, \mathrm{Ca}, \mathrm{Mg}$ elementlerinin içerikleri İndüktif Eşleşmiş Plazma Kütle Spektrometresinde (ICP-MS) saptanmıştır. Meyvede toplam azot içeriği Kjeldahl yöntemi ile belirlenmiştir (Bremner, 1965). Meyvede fosfor ve potasyum içeriği Kaçar (1995)'in bildirdiği metoda göre tespit edilmiştir. Araştırma toprağının analiz metotları (saturasyon, $\mathrm{pH}$, tuzluluk, kireç, organik madde, fosfor, potasyum, bünye) Kaçar (1995)'in bildirdiği metotlar kullanılarak belirlenmiştir.

\section{Bulgular ve Tartışma \\ Meyvelerin makro element içerikleri (N, P, K, Ca ve $\mathrm{Mg}$ )}

Çalışmadan elde edilen bulgulara göre, domates genotiplerinin meyveleri arasındaki makro elementlerden (Çizelge 4) ortalama azot değerleri dikkate alındığında, en yüksek azot içeriği olarak \%2.9 ile Aspem genotipinde, en düşük azot değeri ise \%2.2 ile Karaçor geneotipinde belirlenmiştir. Domates genotiplerinin meyvelerinin azot içerikleri açısından sıralandığında; Aspem > Guldar > Kuzeyköy > Bin101 > Bin109 > Lice > Karaçor şeklindedir.

Çalışmanın sonuçlarına göre, ele alınan domates genotiplerinin meyvelerinin ortalama fosfor içerikleri incelendiğinde, en yüksek fosfor değerinin \%0.62 ile Guldar genotipinde, en düşük fosfor değerinin ise \%0.19 ile Kuzeyköy geneotipinde olduğu belirlenmiştir. Domates genotiplerine ait meyvelerinin $P$ içerikleri sıralandığında; Guldar > Lice > Aspem > Karaçor > Bin101 > Bin109 > Kuzeyköy şeklinde olduğu ortaya çıkmıştır.

Çalışmadan elde edilen potasyum verileri değerlendirildiğinde, ele alınan domates genotiplerinin meyvelerinin ortalama $\mathrm{K}$ içeriklerinin, en yüksek $\% 6.65$ ile Guldar genotipinde, en düşük değerin ise \%3.65 ile Bin109 genotipinde olduğu ortaya çıkmıştır. Buna göre, domates genotiplerine ait meyvelerinin $\mathrm{K}$ içerikleri açılarından sıraya tabii tutulduğunda bu 
Çizelge 1. Araştırmada kullanılan domates genotipleri ve erişim kaynakları

\begin{tabular}{llr}
\hline No & Genotip & Menşei \\
\hline 1 & ASPEM & Asgen Tarım \\
2 & BiN101 & Bingöl-Merkez \\
3 & BiN109 & Bingöl-Ilıcalar \\
4 & GULDAR & Bingöl-Akdurmuş (Guldar) \\
5 & KARAÇOR & Elazı̆g-Kovancılar \\
6 & KUZEYKÖY & Nadide Tohum \\
7 & LiCE & Diyarbakır-Lice \\
\hline
\end{tabular}

Çizelge 2. Araştırmanın yapıldığı toprağın analizleri

\begin{tabular}{|c|c|c|}
\hline Yapılan analiz & Analiz sonucu & Açıklama \\
\hline Saturasyon, \% & 53 & \\
\hline $\mathrm{pH}$ & 6.80 & Hafif asidik \\
\hline Elektriksel iletkenlik (EC), dS/m & 1.65 & Tuzsuz \\
\hline Tuz, \% & 0.06 & \\
\hline Organik madde, \% & 3.54 & Orta düzeyde \\
\hline Kireç $\left(\mathrm{CaCO}_{3}\right), \%$ & 0.16 & Kireçsiz \\
\hline Potasyum $\left(\mathrm{K}_{2} \mathrm{O}\right), \mathrm{kg} / \mathrm{da}$ & 88 & Yeterli düzeyde \\
\hline Fosfor $\left(\mathrm{P}^{2} \mathrm{O}_{5}\right), \mathrm{kg} / \mathrm{da}$ & 11.3 & Yeterli düzeyde \\
\hline Kil, \% & 34.16 & Bünye sınıfı \\
\hline Silt, \% & 31.28 & $(\mathrm{CL})$ \\
\hline Kum, \% & 34.56 & Killi Tın \\
\hline
\end{tabular}

Çizelge 3. Araştırma süresince gerçekleşmiş olan iklim verileri

\begin{tabular}{lrrrrrrr}
\hline İklim parametreleri & Mart & Nisan & Mayıs & Haziran & Temmuz & Ağustos & Eylül \\
\hline Ortalama maksimum sıcaklık $\left({ }^{\circ} \mathrm{C}\right)$ & 8.3 & 12.8 & 23.5 & 30.0 & 31.7 & 33.1 & 22.8 \\
Ortalama minumum sıcaklık $\left({ }^{\circ} \mathrm{C}\right)$ & 1.0 & 4.1 & 10.0 & 161 & 17.7 & 18.9 & 12.3 \\
Ortalama sıcaklık $\left({ }^{\circ} \mathrm{C}\right)$ & 4.0 & 8.3 & 17.3 & 23.6 & 25.2 & 26.1 & 20.6 \\
Aylık ortalama nispi nem $(\%)$ & 68.0 & 70.0 & 49.3 & 37.8 & 31.8 & 30.5 & 34.3 \\
Aylık toplam yağış $(\mathrm{mm})$ & 121.7 & 183.0 & 75.5 & 3.6 & 3.6 & 44.6 & - \\
\hline
\end{tabular}

Çalışmanın kalsiyum sonuçlarına göre, ele alınan domates genotiplerinin meyvelerinin ortalama Ca içerikleri, en yüksek değer olarak \%0.24 ile Kuzeyköy genotipinde, en düşük değer olarak \%0.12 ile Guldar genotipinde belirlenmiştir. Bu sonuçlar dikkate alınarak domates genotiplerine ait meyvelerinin $\mathrm{Ca}$ içerikleri bir sıralamaya tabii tutulduğunda bunun; Kuzeyköy > Karaçor > Lice > Aspem > Bin109 > Bin101 > Guldar şeklinde olduğu ortaya çıkmıştır. Çalışmanın verileri dikkate alındığında magnezyum içerikleri açısından, ele alınan domates genotiplerinin meyvelerinin ortalama $\mathrm{Mg}$ içeriklerinin en yüksek değeri \%0.315 ile Lice genotipinde, en düşük değeri \%0.225 ile Aspem genotipinde olduğu tespit edilmiştir. Bu sonuçlara göre ele alınan domates genotiplerinin meyvelerindeki $\mathrm{Mg}$ içerikleri sıralandığında; Kuzeyköy > Lice > Karaçor > Bin109 > Aspem > Bin101 > Guldar şeklinde bir sıralamanın olduğu ortaya çıkmıştır. 
Çizelge 4. Denemeye alınan domates genotiplerine ait meyvelerdeki makro element değerleri (maksimumminumum değerler)

\begin{tabular}{llllll}
\hline Genotipler (Bölge-Menşe) & $\mathrm{N}$ & $\mathrm{P}$ & $\mathrm{K}$ & $\mathrm{Ca}$ & $\mathrm{Mg}$ \\
\hline & & & $\%$ & & \\
\hline Guldar (Bingöl) & $2.3-2.7$ & $0.55-0.69$ & $6.0-7.7$ & $0.11-0.13$ & $0.21-0.26$ \\
Bin101 (Bingöl) & $2.2-2.5$ & $0-17-1.25$ & $4.9-5.2$ & $0.12-0.13$ & $0.23-0.25$ \\
Bin109 (Bingöl) & $2.2-2.5$ & $0.15-0.24$ & $3.5-3.8$ & $0.12-0.13$ & $0.23-0.28$ \\
Aspem (Ticari) & $2.8-3.0$ & $0.35-0.47$ & $5.2-5.7$ & $0.12-0.15$ & $0.22-0.23$ \\
Lice (Diyarbakır) & $2.2-2.3$ & $0.48-0.52$ & $5.2-5.6$ & $0.20-0.25$ & $0.28-0.35$ \\
Kuzeyköy (Ticari) & $2.2-2.6$ & $0.16-0.22$ & $5.7-7.6$ & $0.23-0.25$ & $0.29-0.33$ \\
Karaçor (Elazığ) & $2.1-2.3$ & $0.21-0.27$ & $5.6-7.5$ & $0.21-0.23$ & $0.27-0.30$ \\
\hline
\end{tabular}

Meyvelerin mikro element içerikleri $(\mathrm{Cu}, \mathrm{Zn}$ ve $\mathrm{Mn})$

Çalışmadaki analiz edilen domates genotiplerinin meyvelerindeki mikro besin elementlerinden bakır elementinin değerleri incelendiğinde (Çizelge 5), en yüksek Cu içeriği ortalama değerinin $5.55 \mathrm{mg} 100 \mathrm{~g}^{-1}$ ile Bin101 genotipinde, en düşük Cu değerinin ise $1.6 \mathrm{mg} 100$ $\mathrm{g}^{-1}$ ile Kuzeyköy ve Karaçor genotiplerinde olduğu belirlenmiştir. Domates genotiplerinin meyveleri bakır içerikleri açısından sıralandığında; Bin109 > Bin101 > Lice > Aspem > Guldar > Kuzeyköy > Karaçor şeklinde bir sıralamanın olduğu ortaya çıkmıştır.

Çalışmadaki analiz edilen domates genotiplerinin meyvelerindeki mikro besin elementi içeriklerinden çinko elementinin değerleri dikkate alındığında, en yüksek ortalama Zn içeriği değerinin 3.85 mg $100 \mathrm{~g}^{-1}$ ile Karaçor genotipinde, en düşük ortalama $\mathrm{Zn}$ değerinin ise $2.6 \mathrm{mg} 100 \mathrm{~g}^{-1}$ ile Bin109 genotipinde olduğu belirlenmiştir. Domates genotiplerinin meyvelerinin çinko içerikleri büyükten küçüğe bir sıralamaya tabii tutulduğunda; Karaçor > Kuzeyköy > Aspem > Bin101 > Guldar > Lice > Bin109 şeklinde bir sıralamanın olduğu belirlenmiştir.

Çalışmada incelenen domates genotipleri meyvelerinin mikro besin elementlerinden mangan elementinin değerleri dikkate alındığında, en yüksek ortalama Mn içeriği değerinin 1.75 mg 100 $\mathrm{g}^{-1}$ ile Guldar genotipinde, en düşük ortalama $\mathrm{Mn}$

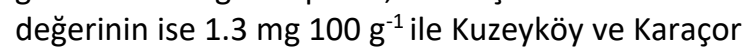
genotiplerinde olduğu tespit edilmiştir. İncelenen farklı genotiplere ait olan domates meyvelerinin mangan değerleri büyükten küçüğe doğru sıralama yapıldığında aşağıdaki belirtilen sıranın ortaya çıktığı gözlenmiştir; Guldar > Bin109 > Aspem > Lice > Bin101 > Kuzeyköy > Karaçor.
Çizelge 5. Denemeye alınan domates genotiplerine ait meyvelerdeki mikro element değerleri (maksimum-minumum değerler)

\begin{tabular}{lccc}
\hline $\begin{array}{l}\text { Genotipler } \\
\text { (Bölge-Menşe) }\end{array}$ & $\mathrm{Cu}$ & $\mathrm{Zn}$ & $\mathrm{Mn}$ \\
\hline \multicolumn{4}{c}{$\mathrm{mg} \mathrm{100} \mathrm{g}^{-1}$} \\
\hline Guldar (Bingöl) & $1.1-1.2$ & $3.2-3.9$ & $1.6-1.9$ \\
Bin101 (Bingöl) & $5.2-5.9$ & $3.2-3.8$ & $1.4-1.5$ \\
Bin109 (Bingöl) & $2.4-2.7$ & $2.5-2.7$ & $1.6-1.8$ \\
Aspem (Ticari) & $2.4-2.7$ & $3.5-3.9$ & $1.5-1.8$ \\
Lice (Diyarbakır) & $4.1-4.6$ & $3.2-3.6$ & $1.5-1.8$ \\
Kuzeyköy (Ticari) & $1.5-1.7$ & $3.7-3.9$ & $1.1-1.5$ \\
Karaçor (Elazığ) & $1.3-1.7$ & $3.7-4.0$ & $1.0-1.6$ \\
\hline
\end{tabular}

\section{Sonuç ve Öneriler}

Ülkemizdeki değişik bölgelere has ürün olduğu (örneğin Çukurova yöresinde pamuk, Doğu Karadeniz bölgesinde çay, Akdeniz yöresinde narenciye) gibi, iller bazında da oldukça zengin ve çeşitli bitkisel özel bir ürün veya birkaç ürünlerin mevcut olduğu (Gaziantep'te antepfıstığı, Bursa'da şeftali, Malatya'da kayısı, Kastamonu'da sarımsak gibi) ve bunların artık o yöre ile bütünleşik bir hal aldığı bilinmektedir. Bu değerler zincirine son yıllarda yeni ve çok değişik ürünler katılmaktadır. Bunlardan biri olma özelliğini kazanabilecek bir ürün de Doğu Anadolu'nun Bingöl ilinin belirli Akdurmuş köyü (eski ismi Guldar) ile bilinen Guldar domatesidir.

Ürünlerin diğer ürünlerde ayrımlı olarak ortaya çıkması tabii ki kendine has özelliklerinin olması iledir. Bu kapsamda, yörede yürütülen bu araştırmada, Guldar domatesi ile yörede yetiştiriciliği yapılan diğer sofralık domates genotiplerine ait meyvelerin makro ve mikro besin 
elementi değerleri belirlenmiş ve karşılaştırmaları yapılmıştır.

Elde edilen sonuç verilen literatürlerle uyum içerisinde olduğu tespit edilmiştir.

Incelenen besin elementlerinden fosfor, potasyum ve manganın Guldar domates genotipinde diğer ele alınan genotiplere nazaran daha fazla olduğu tespit dilmiştir. Bir veya birkaç kriter veya özelliğin (bu özellik morfolojik, fiziksel, kimyasal veya verim açısından olabilir) diğerlerinden farklı veya yüksek olması o ürünü diğerlerinden farklı özelliklere sahip olmasına neden olabilir.

Bu bağlamda, Guldar domatesinin besin elementi olarak önemli olan elementlerden fosfor, potasyum ve mangan içeriklerinin diğer karşılaştırma yapılmak için ele alınan domates genotiplerinden daha fazla konsantrasyonda olması, onu yöreye has bir ürün olarak öne çıkarmaktadır. Aynı zamanda fosfor, potasyum ve mangan elementlerinin çok tüketilen bu gıdada bulunması insan sağlığı açısından da oldukça önemlidir. Yine, önceki çalışmalarda da belirtilen bu ürünün verimini fazla ve tadının kendine özel olması da (Özbay. 2021) bu ürünü öne çıkaran diğer kriterler olarak kabul edilebilir.

Teşekkür: Bu çalışmaya destek veren Bingöl Tarım ve Orman İ Müdürlüğü yöneticilerine, Örneklerin tedariki aşamalarında yardımları olan Ziraat Mühendisi Ahmet Bozaba'ya, örneklerin laboratuvar analizleri aşamalarında yardımlarını esirgemeyen Ziraat Yüksek Mühendisi Kadriye Ateş'e, Araştırma Görevlisi Orhan İnik'e, Doç. Dr. Ferdi Akman'a ve Akdurmuş Köyü Muhtarı Mahmut BAHADIR'a teşekkür ederim.

Çıkar Çatışması Beyanı: Makale yazarı herhangi bir çıkar çatışması olmadığını beyan eder.

\section{Kaynaklar}

Bjelić, V., Moravčević. D., Beatović, D. 2005. Effect of greenhouse conditions on $\mathrm{Zn}, \mathrm{Fe}$ and $\mathrm{Cu}$ Content in Tomato Fruits. Journal of Agricultural Sciences, 50(2): 101-105.

Bosiacki, M., Wojciech Tyksiñski, W. 2009. Copper, zınc, Iron and manganese content in edıble parts of some fresh vegetables sold on markets ın poznañ. J. Elementol., 14(1): 1322.

Bremner, J.M. 1965. Total Nitrogen. Editor C.A.BLACK:Methods of Soil Analysis.Part 2 Amer.Society of Agronomy Inc.,Publicher, Madison, Wisconsin, U.S.A.1149-1178.

Budak, Z. 2015. Sera koşullarında yapraktan kalsiyum uygulamasının domates çeşitlerinin gelişim, verim ve mineral beslenmesine etkisi. Süleyman Demirel Üniversitesi Fen Bilimleri Enstitüsü Toprak Bilimi ve Bitki Besleme Anabilim Dalı, Isparta, Yüksek Lisans Tezi.

Ceylan, Ş., Mordoğan, N., Yoldaş, F., Yağmur, B. 2001. Azotlu gübrelemenin domates bitkisinde verim, azot birikimi ve besin element içeriği üzerine etkisi, Ege Üniversitesi Ziraat Fakültesi Dergisi, 38(23):103-110.

Codex Alimentarius Commission (CAS). 2001. Food additives and contaminants. Joint FAO/WHO Food Standards Programme. ALINORM 01(12A):1-289.

Codex Alimentarius Commission (CAS). 2011. Joint FAO/WHO food standards programme, codex committee on contaminants in foods, working document for information and use in discussions related to contaminants and toxins in the GSCTFF, CF/5 INF/1

Dere, S., Daşgan, H.Y., Akhoundnejad, Y., Kafkas, N.E. 2018. Yüksek sıcaklık stresine tolerant domates genotiplerinin meyvede mineral içeriği bakımından taranması, Yüzüncü Yıl Üniversitesi Tarım Bilimleri Dergisi, 28: 307314.

Dorais, M., Ehret, D.L., Papadopoulos, A.P. 2008. Tomato (Solanum lycopersicum) health components: from the seed to the consumer. Phytochem Rev., 7: 231-250.

Fernandez-Ruiz, V., Olives, A.I., Camara, M., Sanchez-Mata, M.C., Torija, M.E. 2011. Mineral and Trace Elements Content in 30 Accessions of Tomato Fruits (Solanum lycopersicum L.,) and Wild Relatives (Solanum pimpinellifolium L., Solanum cheesmaniae L. Riley, and Solanum habrochaites S. Knapp \& D.M. Spooner). Biological Trace Element Research, 141: 329-339.

Guil-Guerrero, J.L., Rebolloso-Fuentes, M.M. 2009. Nutrient composition and antioxidant activity of eight tomato (Lycopersicon esculentum) varieties. Journal of Food Composition and Analysis, 22: 123-129.

Gunderson, V., McCall, D., Bechmann, I.E. 2001. Comparison of major and trace element concentrations in Danish greenhouse tomatoes (Lycopersicon esculentum Cv. Aromata F1) cultivated in different sustrates. J. Agric. Food Chem., 49: 38083815.

Hernandez Suarez, M., Rodriguez Rodriguez, E., Diaz Romero, C. 2007. Mineral and trace element concentrations in cultivars of tomatoes. Food Chemistry, 104: 489-499. 
Jones J.B., Wolf, Jr. B., Mills, H.A. 1991. Plant Analysis Handbook. I. Methods of Plant Analysis and Interpratation. Micro-Macro Publishing Inc.,183 Paradise Blvd, Suite 108, Athens Georgia 30607 USA.

Kacar,B., 1995. Bitki ve Toprağın Kimyasal Analizleri. Toprak Analizleri. A.Ü.Ziraat Fak.Eğitim Araştırma ve Geliştirme Vakfı Yayınları: 3, Ankara.

Lente, I., Ofosu-Anim, J., Brimah, A.K., Atiemo, S. 2014. Heavy metal pollution of vegetable crops irrigated with wastewater in Accra, Ghana. W. Afr. J. Appl. Ecol. 22:41-58.

Özbay, N. 2021. 'Guldar' domatesinin coğrafi işaret almasına yönelik yürütülen arazi ve laboratuvar çalışmaları. Türk Tarım ve Doğa Dergisi, 8(2): 492-500.

Premuzic, Z., Bargiela, M., Garcia, A., Rendina, A., Loria, A. 1998. Calcium, iron, potassium, and vitamin $C$ content of organic and hyroponic tomatoes. Hort.Science, 33(2): 255-257.

Rijck, G., Schrevens, E. 1998. Mixture optimization of the mineral nutrition of tomatoes in relation to mineral content of the fruit: effects of preharvest factors on fruit quality. Acta. Hort. 464: 485.

Sainju, U.M.,, Dris, R., Singh, B. 2003. Mineral nutrition of tomato. Food, Agriculture and Environment, 1(2): 176-183.

Sainju UM, Dris R, Singh B (2014). Mineral Nutrition of tomato.

https://www.researchgate.net/publication/228960 277_Mineral_nutrition_of_tomato.

Sanders, D.C., Grayson, A.S., Monaco, T.J. 1981. Mineral Content of Tomato (Lycopersicon esculentum) and Four Competing Weed Species. Weed Science, 29: 590-593.

Söylemez, S., Pakyürek, A.Y. 2017. Domates meyvesinin element içeriği üzerine farklı anaçların ve besin kaynaklı EC seviyelerinin etkisi. Türk Tarım ve Doğa Bilimleri Dergisi, $4(2): 155-161$. 